\title{
Evaluation of Saccule Function in Patients with Vitamin D Deficiency
}

\author{
Hossein Talebi ${ }^{1}$, Marziyeh Moallemi ${ }^{1,2}$, and Mitra Ghorbani ${ }^{1}$ \\ 'Department of Audiology, Faculty of Rehabilitation, Communication Disorders Research Center, Isfahan University of Medical Sciences, \\ Isfahan, Iran \\ ${ }^{2}$ Department of Audiology, Faculty of Rehabilitation, Iran University of Medical Sciences, Tehran, Iran
}

\author{
Received June 22, 2018 \\ Revised August 11, 2018 \\ Accepted August 14, 2018
}

Background and Objectives: Considering important role of vitamin D in many physiological processes including vestibular system in the ear, aim of present study is to evaluate saccule function via cervical vestibular evoked myogenic potential (cVEMP), in patients with vitamin $\mathrm{D}$ deficiency. Subjects and Methods: After routine audiological tests, cVEMP were recorded in 15 patients with vitamin D deficiency and 16 normal subjects. The short tone burst (95 dB $\mathrm{nHL}, 500 \mathrm{~Hz}$ ) was presented to ears. cVEMP was recorded with surface electromyography over the contracted ipsilateral sternocleidomastoid muscle. Results: Mean of p13, n13, interpeak latencies and amplitude ratios were measured in both groups. Statistical analysis did not show differences between two groups. Conclusions: Maybe serum 25-hydroxyvitamin D concentration was not low enough to have effect on saccule in the patients in present study or saccule have had low susceptibility to effects of vitamin D deficiency. For better judgment about effect of vitamin D deficiency on saccular function planning studies with high sample size is recommended.

J Audiol Otol 2019;23(1):49-52

KEY WORDS: Saccule · Vitamin D deficiency · Cervical vestibular evoked myogenic potential.

\section{Introduction}

Vitamin D is one of the fat-soluble vitamins that plays a role in many physiological processes. With the finding of the vitamin D receptor in almost every tissue and tuning thousands of genes with this vitamin, the interest in studying vitamin D and its effects on physiological processes has accelerated greatly [1-4]. On the other hand, it is estimated that around one billion people worldwide suffer from vitamin D deficiency or insufficiency. The major source of vitamin D for most humans is exposure to sunlight. The higher prevalence of vitamin D deficiency in Middle Eastern and Asian countries, including Iran, despite the proper annual sunlight, is largely due to inadequate exposure to sunlight because of the type of clothing or the avoidance of sun exposure to prevent skin problems $[5,6]$. The results of studies in Iran have shown a high preva-

This is an Open Access article distributed under the terms of the Creative Commons Attribution Non-Commercial License (https://creativecommons.org/licenses/by-nc/4.0/) which permits unrestricted non-commercial use, distribution, and reproduction in any medium, provided the original work is properly cited. lence of vitamin D deficiency among different age groups. The results of studies in Isfahan, a sunny city in the center of Iran, show a high incidence of vitamin D insufficiency and deficiency $(50.8 \%)$ among adults [6-11]. Considering the presence of vitamin D receptor in the inner ear, it seems logical that the deficiency of this vitamin can cause problems in this part. It is reported that the incidence of vitamin D deficiency is extremely common in Ear, Nose, Throat (E.N.T.) patients [12,13]. Several studies have reported the important role of vitamin D for the normal vestibular and hearing function [2,12-18]. A study on ten patients with bilateral cochlear hearing loss reported a relationship between their hearing loss and vitamin $\mathrm{D}$ deficiency [15]. The most likely cause for such condition according to this study is the demineralization of the cochlea resulting in a metabolic type of sensorineural hearing loss. Therefore Vitamin D deficiency must be considered in the differential diagnosis of idiopathic bilateral cochlear hearing loss. Animal studies have shown that vitamin D receptor dysfunction is associated with ear development, hearing loss and vestibular disorders $[2,12,16,17]$. It has also been reported that 
genetic mutation in the vitamin $\mathrm{D}$ receptor gene can contribute to the etiology of otosclerosis; also, deficient activity of vitamin D is important in the etiology of otosclerosis and presbycusis [18]. Several studies on benign paroxysmal positional vertigo (BPPV) have shown the correlation between BPPV and disorders such as diabetes, chronic thyroid disease, hypertension, osteoporosis, and vitamin D deficiency. Among these diseases, association with osteoporosis and vitamin D deficiency implies that abnormal calcium metabolism may be responsible for the incidence of BPPV. Since the otoconia within the utricle of the inner ear consists calcium carbonate, this condition is attributed to a possible disorder in the level of vestibular endolymph calcium ion which results in abnormal otoconia formation. It is assumed that if vitamin D deficiency leads to otoconial abnormalities in the utricle and hence BPPV, then there may be a possibility of otolith dysfunction in saccule too $[5,16,19]$. Therefore it may be reasonable to evaluate probable saccule abnormality in vitamin D deficiency. The cervical vestibular evoked myogenic potential (cVEMP) test is a clinical tool widely used to evaluate saccule function. The present study aims to investigate possible changes in the findings of cVEMP test in patients with vitamin D deficiency.

\section{Subjects and Methods}

This research is a cross-sectional, descriptive-analytic study. Individuals in the patient group included a number of subjects with vitamin D deficiency referred to internal diseases clinic of Al-Zahra Hospital of Isfahan University of Medical Sciences whose disease has been diagnosed by expert physicians. The criteria for inclusion in the study include: vitamin D deficiency according to serum 25-hydroxyvitamin D concentrations $<30 \mathrm{ng} / \mathrm{mL}$ for the, age less than 60 years, normal bone mineral density, normal middle ear condition, absence of cervical problems, no history of other neurological and metabolic diseases, and no history of any hearing loss or balance disorders. The control group consisted of normal people without any history of vitamin D deficiency and other aforementioned diseases which matched in age and gender with the patient group. After obtaining informed consent and describing the test method, history taking was done for all patients. Then otoscopic examinations, pure tone audiometry, tympanometry, and auditory reflex test were performed. After ensuring the health of the conductive auditory system, the cVEMP test was be implemented at the Vestibular Research Center at Al-Zahra Hospital in both groups. The test was performed with an auditory evoked potential apparatus (Eclipse, Interacoustics, Middelfart, Denmark). Short tone bursts of
$500 \mathrm{~Hz}$ with $2 \mathrm{~ms}$ rise/fall times and plateau $0 \mathrm{~ms}$ with stimulation rate of $5.1 / \mathrm{sec}$ and rarefaction polarity presented to the ear ipsilateral to the contracted sternocleidomastoid (SCM) muscle through the insert earphone (ER-3A). Stimulus intensity was $95 \mathrm{~dB}$. Analysis time for each stimulus was $100 \mathrm{~ms}$. Responses up to 150 stimuli were averaged for each test and band-pass filtered from $10-1,500 \mathrm{~Hz}$ [20]. The electrodes placement was such that the non-inverting electrode is placed on the middle part of the SCM muscle, the reference electrode between the clavicles, and the ground electrode on the forehead [21]. In order to test the repeatability of the response, the cVEMP test was run twice for each ear [22]. To achieve a full contraction of the SCM muscle, the patient sits on a chair and turns his head 80 degrees to the opposite side of the tested muscle [23]. In order to control electromyography, the contraction level of SCM muscle should be constant during the test, and a feedback technique was used to create an equal contraction in both SCM muscles [24]. Target variables in present study were the absolute and interpeak latency (IPL) and relative amplitude of cVEMP. Finally, the results between the two groups were compared and interpreted. The t-test and MannWithney method were used to analyze the data. SPSS statistical software ver. 20 (IBM Corp., Armonk, NY, USA) performed statistical analyses. A $p$ value $<0.05$ was considered statistically significant. This study was approved by Communication Disorders Research Center of Isfahan University of Medical Sciences (IR.MUI.REC.1395.2.139).

\section{Results}

Audiometry and tympanometry evaluation showed that all subjects in both groups had normal hearing and intact conductive hearing system. Serum 25 hydroxyvitamin D concentrations was $\geq 30 \mathrm{ng} / \mathrm{mL}$ in control group and $<30 \mathrm{ng} / \mathrm{mL}$ in patients group.

The cVEMP responses were recorded in all subjects. Amplitude ratio of response, latency of cVEMP waves and IPL were compared between two groups. Amplitude ratios were calculated as the difference of p13-n23 amplitude in the right and left ears divided by the sum of p13-n23 amplitudes of both ears. In the normal group, the mean $( \pm \mathrm{SD})$ of p13 latency, n23 latency, and IPL were $15.36( \pm 0.57) \mathrm{ms}, 23.82$ ( \pm $0.94) \mathrm{ms}$, and $8.45( \pm 0.72) \mathrm{ms}$, respectively. In the vitamin D deficiency group, the mean ( \pm SD) of p13 latency, n23 latency, and IPL were $14.73( \pm 1.26) \mathrm{ms}, 23.65( \pm 1.55) \mathrm{ms}$, and 8.91 $( \pm 1.49) \mathrm{ms}$, respectively. Because number of participants in each group was lower than 30, we first tested normal distribution of our data for each variable in SPSS software. Except for amplitude ratio, other variables had normal distribution. 
Table 1. Comparison of mean of $p 13$ latency, n23 latency and IPL (in $\mathrm{ms}$ ) between vitamin $\mathrm{D}$ deficiency and normal groups

\begin{tabular}{lccc}
\hline & $\mathrm{p} 13$ & $\mathrm{n} 23$ & $\mathrm{IPL}$ \\
& Mean \pm SD & Mean \pm SD & Mean \pm SD \\
\hline Vitamin D deficiency & $14.73 \pm 1.26$ & $23.65 \pm 1.55$ & $8.91 \pm 1.49$ \\
Normal & $15.36 \pm 0.57$ & $23.82 \pm 0.94$ & $8.45 \pm 0.72$ \\
$\begin{array}{l}\text { Indepndent t-test } \\
\text { ( } \text {-value) }\end{array}$ & 0.08 & 0.71 & 0.28 \\
\hline
\end{tabular}

IPL: interpeak latency

Table 2. Comparison of mean amplitude ratio between vitamin $D$ deficiency and normal groups

\begin{tabular}{lc}
\hline & Amplitued ratio \\
& Mean \pm SD \\
\hline Vitamin D deficiency & $0.17 \pm 0.15$ \\
Normal & $0.08 \pm 0.07$ \\
Mann-Withney ( $p$-value) & 0.17 \\
\hline
\end{tabular}

Independent t-test demonstrated no significant statistical differences between the two groups in latency values $(p>0.05)$ (Table 1).

The mean $( \pm \mathrm{SD})$ amplitude ratio was $0.08( \pm 0.07)$ in the control group and $0.17( \pm 0.15)$ in vitamn D deficiency patients. Statistical analysis by Mann-Withney test did not show significant differences between the vitamin D deficiency and control groups in amplitude ratio $(p>0.05)$ (Table 2).

\section{Discussion}

Comparison of the results in our study did not show significant differences between vitamin D deficiency patients and normal groups in none of cVEMP parameters including latencies and amplitude ratio. We used amplitude ratio because absolute amplitude has very varieties. cVEMPs were recorded in all subjects and we had no absent cVEMP. According to our best knowledge only one study investigated cVEMP responses in patients with vitamin D deficiency. In that study VEMP responses including cVEMP and ocular vestibular evoked myogenic potential (oVEMP) showed some abnormalities. Responses were absent in some patients and delayed in some others. The authors explained for VEMP abnormalities that $\mathrm{Ca}^{2+}$ level must remain in low level in both the cochlea and vestibular system by an absorption system and vitamin $\mathrm{D}$ is necessary for this process and homeostasis of $\mathrm{Ca}^{2+}$ in endolymph and consequently is important for development of otoconia in utricle and saccule. Disturbances in calcium metabolism may generate structural and ultrastructural changes in otoconia that result in otolith dysfunction $[5,14]$.

Our study was only evaluated cVEMP in vitamin D deficiency patients. We assumed vitamin D sufficiency when 25-hydroxyvitamin $\mathrm{D}$ was higher than $30 \mathrm{ng} / \mathrm{mL}$ and lower than that as insufficient or deficient and did not differentiate between insufficiency and deficiency. Differences between our results with pervious study may be related to some reasons such as low number of patients and generally our sample size, consideration only upper and lower than $30 \mathrm{ng} / \mathrm{mL} 25$-hydroxyvitamin $\mathrm{D}$ for being normal or abnormal (because may only very low concentration of vitamin $\mathrm{D}$ affected on vestibular function).

We know cVEMP would mostly reflect the saccular activity. Most studies in vestibular system researches reported changes in utricular otoconia after vestibular diseases and saccule was less affected. So there is a probable that saccule has lower susceptibility to effects of vitamin D deficiency and may be using oVEMP revealed some abnormalities in otolithic organs instead of cVEMP [25].

Low serum level of vitamin $\mathrm{D}$ is sometimes associated with low bone mass. Patients in this study had no bone problems and so probably vitamin D deficiency was not strong enough to effect on vestibular system too [26].

Duration of disease and low sensitivity to vitamin D deficiency in some patients may be are another reasons for our results [5].

We compared IPL in responses between two groups and there was no difference in this parameter between the groups too. It probably showed the central pathways of cVEMP is normal in the patient group.

In conclusion, it is better to do some other cross sectional studies with high sample sizes and with complete vestibular tests and imaging studies for assessment of otoconia and categorize patients according duration of their diseases. Try to fix all other confounding variables is a difficult work and it seems necessity of some other kind of studies such as clinical trials or animal studies.

\section{Acknowledgments}

This study was supported by Isfahan University of Medical Sciences (Study code: 295139).

\section{Conflicts of interest}

The authors have no financial conflicts of interest.

\section{REFERENCES}

1) Bikle DD. Vitamin D metabolism, mechanism of action, and clinical applications. Chem Biol 2014;21:319-29.

2) Zou J, Minasyan A, Keisala T, Zhang Y, Wang JH, Lou YR, et al. Progressive hearing loss in mice with a mutated vitamin $\mathrm{D}$ receptor gene. Audiol Neurootol 2008;13:219-30.

3) Taneja MK, Taneja V. Role of vitamin D in prevention of deafness. Indian J Otol 2012;18:55-7.

4) Holick MF. Vitamin D deficiency. N Engl J Med 2007;357:266-81.

5) Sanyelbhaa H, Sanyelbhaa A. Vestibular-evoked myogenic potentials and subjective visual vertical testing in patients with vitamin D deficiency/insufficiency. Eur Arch Otorhinolaryngol 2015;272:3233-9. 
6) Hovsepian S, Amini M, Aminorroaya A, Amini P, Iraj B. Prevalence of vitamin D deficiency among adult population of Isfahan City, Iran. J Health Popul Nutr 2011;29:149-55.

7) Azizi F, Rais-Zadeh F, Mir Said Ghazi A. Vitamin D deficiency in a group of Tehran Population. Res Med 2000;4:291-303.

8) Hashemipour S, Larijani B, Adibi H, Javadi E, Sedaghat M, Pajouhi $\mathrm{M}$, et al. Vitamin D deficiency and causative factors in the population of Tehran. BMC Public Health 2004;4:38.

9) Moussavi M, Heidarpour R, Aminorroaya A, Pournaghshband Z, Amini M. Prevalence of vitamin D deficiency in Isfahani high school students in 2004. Horm Res 2005;64:144-8.

10) Shahla A, Charehsaz S, Talebi R, Omrani M. Vitamin D deficiency in young females with musculoskeletal complaints in Urmia, Northwest of Iran. Iran J Med Sci 2005;30:88-90.

11) Salek M, Hashemipour M, Aminorroaya A, Gheiratmand A, Kelishadi R, Ardestani PM, et al. Vitamin D deficiency among pregnant women and their newborns in Isfahan, Iran. Exp Clin Endocrinol Diabetes 2008;116:352-6

12) Kwon HJ. Vitamin D receptor deficiency impairs inner ear development in zebrafish. Biochem Biophys Res Commun 2016;478:994-8.

13) Taneja MK, Taneja V. Vitamin D deficiency in E.N.T. patients. Indian J Otolaryngol Head Neck Surg 2013;65:57-60.

14) Yamauchi D, Nakaya K, Raveendran NN, Harbidge DG, Singh R, Wangemann P, et al. Expression of epithelial calcium transport system in rat cochlea and vestibular labyrinth. BMC Physiol 2010;10:1.

15) Brookes GB. Vitamin D deficiency--a new cause of cochlear deafness. J Laryngol Otol 1983;97:405-20.

16) Jeong SH, Kim JS, Shin JW, Kim S, Lee H, Lee AY, et al. Decreased serum vitamin $\mathrm{D}$ in idiopathic benign paroxysmal positional vertigo. J Neurol 2013;260:832-8.
17) Minasyan A, Keisala T, Zou J, Zhang Y, Toppila E, Syvälä H, et al. Vestibular dysfunction in vitamin D receptor mutant mice. J Steroid Biochem Mol Biol 2009;114:161-6.

18) Yıldırım YS, Apuhan T, Düzenli S, Arslan AO. Otosclerosis and vitamin D receptor gene polymorphism. Am J Otolaryngol 2013;34: 454-7.

19) Talaat HS, Abuhadied G, Talaat AS, Abdelaal MS. Low bone mineral density and vitamin $\mathrm{D}$ deficiency in patients with benign positional paroxysmal vertigo. Eur Arch Otorhinolaryngol 2015;272:2249-53.

20) Hall JW. New handbook of auditory evoked responses. Boston (MA): Pearson education Inc; 2007.

21) Vanspauwen R, Wuyts FL, Van De Heyning PH. Validity of a new feedback method for the VEMP test. Acta Otolaryngol 2006;126: 796-800.

22) Liao LJ, Young YH. Vestibular evoked myogenic potentials in basilar artery migraine. Laryngoscope 2004;114:1305-9.

23) Allena M, Magis D, De Pasqua V, Schoenen J, Bisdorff AR. The vestibulo-collic reflex is abnormal in migraine. Cephalalgia 2007;27: 1150-5.

24) Vanspauwen R, Wuyts FL, Van de Heyning PH. Improving vestibular evoked myogenic potential reliability by using a blood pressure manometer. Laryngoscope 2006;116:131-5.

25) Gargeshwari A, Jha RH, Singh NK, Kumar P. Behavioural and objective vestibular assessment in persons with osteoporosis and osteopenia: a preliminary investigation. Braz J Otorhinolaryngol 2017 Sep 21 [Epub]. Available from: https://doi.org/10.1016/j.bjorl.2017.08.013.

26) Sheikhzadeh M, Lotfi Y, Mousavi A, Heidari B, Monadi M, Bakhshi E. Influence of supplemental vitamin D on intensity of benign paroxysmal positional vertigo: A longitudinal clinical study. Caspian J Intern Med 2016;7:93-8. 